\title{
Annotation
}

\section{Horseradish Peroxidase Transport from Primate Dental Pulps}

\author{
Charles F. Cox, Daniel J. Chiego, Jr., James K. Avery, and Bruce E. Bradley
}

Oral Histology Laboratory of the Dental Research Institute and School of Dentistry, University of Michigan, Ann Arbor, Michigan, t48109, USA

\section{J Dent Res 56(10): 1184 October 1977.}

Retrograde axonal transport of horseradish peroxidase (HPR) was first utilized for the tracing of central and peripheral neural pathways by Kristenssen (Acta Neuropath 19:1, 1971). Recent studies by Furstman (Brain Res 84: 320, 1975) and Arvidsson (Brain Res 99:135, 1975 ) have utilized HRP as a retrograde tracer from cat and rat teeth respectively. Their efforts confirmed a somatotopic organization of the trigeminal ganglion nerve cells from specific teeth. Based on these previous reports, we surveyed the primary neurons representing sensory and autonomic innervation of primate tooth pulps.

Three rhesus and two squirrel monkeys were used. Buccal class V cavity preparations were cut from the cuspid to second molars of maxillary and mandibular teeth of the right side. Each pulp was entered without hemorrhage and then injected with a $1 \mu \mathrm{l}$ of $30 \%$ HRP and then covered with zinc oxide and eugenol followed by amalgam to prevent leakage into surrounding tissues. Allowing for a retrograde axonal transport flow of $70 \mathrm{~mm} / 24$ hour, the animals were perfused and the following tissues were dissected and removed: the right and left trigeminal, right and left geniculate, right and left pterygopalatine, right and left otic, right and left superior cervical ganglia, and portions of the brainstem and the thalamus. These tissues were then prepared for both light and electron microscopy.

Localization of HRP was found using both light and electron microscopy in both ipsi- and contralateral trigeminal ganglia (Fig 1). A group of 4 to 10 cells in the ipsilateral pons were also found to be HRP positive at the level of entry of the root of the trigeminal nerve in both species (Fig 2).

The former suggests a bilateral sensory innervation of the dental pulps. This type of transmedian innervation has been physiologically demonstrated for both the upper and lower cuspid teeth of the cat by ANDERson (Exp Neurol 44:35, 1974). The clinical manifestation of cross innervation of anterior teeth has been considered by Howe (Local Anaesthesia in Dentistry, Wright, Bristol, 1972). It is possible that in primate dentitions there is a sensory

This investigation was supported by USPHS Grant DR-01604-13 from the National Institute of Dental Research.

Received for publication April 29, 1977.

Accepted for publication May 24, 1977.

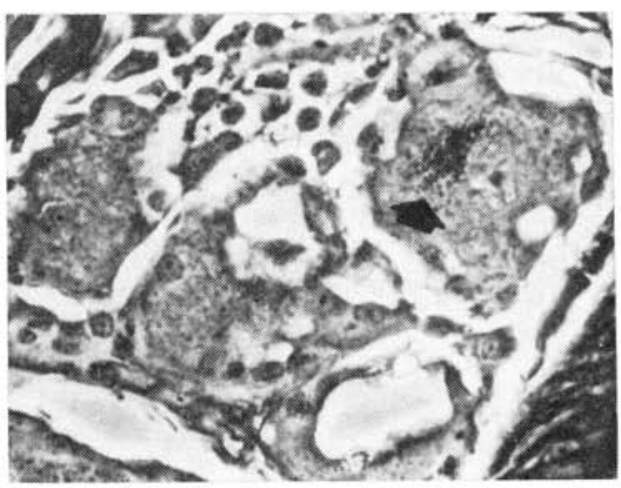

FIg 1.-Left trigeminal ganglion cells with HRP granules at the arrow. Phase contrast ( $X$ $160)$.

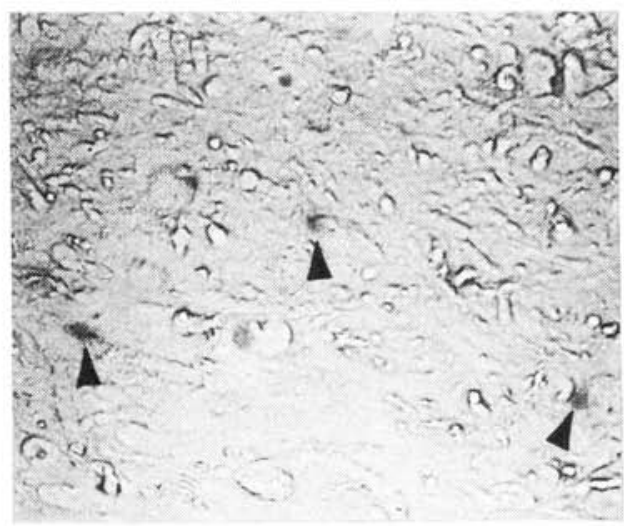

FIG 2.-Right pons with HRP labeled cells at the arrows. Phase contrast $(\times 63)$.

overlap via the mental, or other nerves, being seen in the left trigeminal ganglia as a representation of contralateral innervation. The pontine localization indicates primary afferent innervation from cell bodies that are located within the central nervous system, since no evidence of trans-synaptic migration of HRP is known.

The remaining tissues are currently being quantitatively analysed, by both light and electron microscopy, for somatotopic representation and cell density of the individual teeth. 